\title{
Dasar Filosofi Marketing Syari’ah
}

\author{
Moh. Muzwir R. Luntajo
}

\begin{abstract}
Syariah marketing is an business process which the was entirety of process of applying Islam values. Any way how to make business process placing forward justice values and sincerity. Syari'ah marketing is a strategic business discipline which instruct creation process, offer, and change of value from an inisiator to stakeholder, which in all the process of as according to elementary principles and akad [of] muamalah (bisnis) in Islam. Especial Elementary in application of Syariah marketing is all fundamental theorems concerning business of Islam, what included in Al Holy, Hadis Prophet, and also various moslem scholar religious advices.
\end{abstract}

\section{Kata Kunci : Marketing, Syariah, Bisnis Islam}

\section{Pendahuluan}

Marketing merupakan sebuah disiplin bisnis strategis yang mengarahkan pada proses penciptaan, penawaran dan perubahan dari nilai dari satu inisiator kepada stakeholdernya. Kegiatan marketing sebenarnya merupakan kegiatan yang sangat mulia karena pada kegiatan tersebut selalu memunculkan ide dan kreativitas untuk melakukan approach, inovativ, perubahan dan pembaharuan dalam banyak hal.

Namun, ketika kegiatan tersebut mengalami disorientasi dan cenderung mengejar keuntungan yang instan, maka terkadang kegiatan marketing yang mulia dan penuh etika itu telah berubah dengan penipuan dan manipulasi. Fenomena itulah yang acapkali kita lihat di lapangan. Para marketer dalam melakukan entertaint marketing selama ini banyak sekali melakukan penyimpangan-penyimpangan secara etika dan moral. Apabila fenomena itu terus dipertahankan maka akan merusak dunia peradaban marketing.

Saat ini tatkala bisnis syariah sedang banyak digandrungi, ada beberapa pendapat yang mengatakan pasar syariah adalah pasar yang emosional (emotional market) sedangkan pasar konvensional adalah pasar yang rasional (rational market). Maksudnya orang tertarik untuk berbisnis pada pasar syariah karena alasan-alasan keagamaan (dalam hal ini agama Islam) yang lebih bersifat emosional, bukan karena ingin mendapatkan keuntungan financial yang bersifat rasional. Sebaliknya, pada pasar konvensional atau non-syariah, orang ingin mendapatkan keuntungan yang sebesar-besarnya, tanpa terlalu peduli apakah bisnis yang digelutinya tersebut mungkin menyimpang atau malah bertentangan dengan ajaran agama (Islam).

Pernyataan ini sebenarnya tidak sepenuhnya benar, karena membuat seolah-olah ada dikotomi antara pasar emosional dan pasar rasional. Cara berpikir seperti itu dilandasi oleh teori marketing konvensional yang berpaham kapitalis-sekuler, dimana segala hal yang berlandaskan cara berpikir keagamaan serta-merta akan dianggap sebagai sesuatu yang tidak rasional. 
Memang praktisi bisnis dan marketing sebenarnya bergeser dan mengalami transformasi dari level intelektual (rasional) ke emosional dan akhirnya ke pasar spiritual. Pada akhirnya konsumen akan mempertimbangkan kesesuaian produk dan jasa terhadap nilai-nilai spiritual yang diyakininya. ${ }^{1}$

Pada level Intelektual (rasional), pemasar menyikapi pemasaran secara fungsional-teknikal dengan menggunakan sejumlah tools pemasaran, seperti segmentasion, targeting, positioning, marketing-mix, branding dan sebagainya. Kemudian di level emosional, kemampuan pemasar dalam memahami emosi dan perasaan pelanggan menjadi penting. Di sini pelanggan dilihat sebagai manusia seutuhnya, lengkap dengan emosi dan perasaannya.

Spiritual marketing merupakan tingkatan tertinggi. Orang tidak semata-mata menghitung untung atau rugi, tidak terpengaruh lagi dengan hal yang bersifat duniawi. Panggilan jiwalah yang mendorongnya, karena di dalamnya terkandung nilai-nilai spiritual.

Selain itu dalam syariah marketing, bisnis yang disertai keikhlasan semata-mata hanya untuk mencari keridhaan Allah, maka seluruh bentuk transaksinya insya Allah menjadi ibadah dihadapan Allah. Ini akan menjadi bibit dan modal dasar baginya untuk tumbuh menjadi bisnis yang besar, yang memiliki spiritual brand, yang memiliki karisma, keunggulan, dan keunikan yang tak tertandingi.

Stephen R. Covey penulis buku "The 7 Habit of Highly Effective People", di penghujung karirnya dia menerbitkan buku baru, "The $8^{\text {th }}$ Habit : From Effectiveness to Greatness", menyimpulkan bahwa faktor spiritual merupakan kunci terakhir yang harus dimiliki seorang pemimpin dalam suatu perusahaan. Kita perlukan kepemimpinan spiritual dalam mengelola suatu bisnis, terlepas dari mana sumber spiritual tersebut.

Suatu bisnis, sekalipun bergerak dalam bisnis yang berhubungan dengan agama, jika tidak mampu memberikan kebahagiaan kepada semua pihak, berarti belum melaksanakan spiritual marketing. Sebaliknya jika dalam berbisnis kita sudah mampu memberikan kebahagiaan, menjalankan kejujuran dan keadilan, sesungguhnya kita telah menjalankan spiritual marketing, apapun bidang yang kita geluti. Dalam bisnis travel haji misalnya, sekalipun mengurusi orang yang sedang menjalankan ibadah haji, jika dalam pengelolaannya terdapat penyimpangan-penyimpangan dari segi fasilitas dan akomodasi setelah di Tanah Suci, tidak sesuai dengan yang dijanjikan dan dipromosikan sebelumnya, berarti sesungguhnya bisnis ini tidak berjalan dengan konsep bisnis syariah. Iapun belum menjalankan spiritual marketing.

\section{Karakteristik Syariah Marketing}

Profesor Philip Kotler mendefinisikan: "marketing is a societal process by which individuals and groups obtain what they need and want through creating, offering, and exchanging

\footnotetext{
${ }^{1}$ Baca lebih lanjut Danah Zohar \& Ian Marshall, Spiritual Capital: Wealth We Can Live by Using Our Rational, Emotional, and Spiritual Intelligence to Transform Ourselves and Corporate Culture, (London: Bloombury Publishing Plc, 2004)

${ }^{2}$ Stephen R. Covey, The $8^{\text {th }}$ Habits From Effectiveness to Greatness (New York, London, Toronto, Sydney: Simon Schuster, 2004).
} 
products and services of value freely with others. ${ }^{3}$ Sedangkan ruang lingkupnya The Scope of Marketing masih menurut Kotler, meliputi hal-hal "marketing people are involved in marketing 10 types of entities: goods, services, experiences, events, persons, places, properties, organizations, information, and ideas. ${ }^{4}$

Sedangkan definisi marketing menurut World Marketing Association (WMA) yang diajukan oleh Hermawan Kartajaya dan sudah dipresentasikan di World Marketing Conference di Tokyo pada April 1998 adalah: "marketing adalah sebuah disiplin bisnis strategis yang mengarahkan proses penciptaan, penawaran, dan perubahan value dari satu inisiator kepada stakeholder-nya."

Dengan demikian, maka syariah marketing adalah sebuah disiplin bisnis strategis yang mengarahkan proses penciptaan, penawaran, dan perubahan value dari suatu inisiator kepada stakeholder-nya, yang dalam keseluruhan prosesnya sesuai dengan akad-akad dan prinsipprinsip muamalah (bisnis) dalam Islam.

Kata "syariah" (al-syari'ah) itu sendiri telah ada dalam bahasa Arab sebelum turunnya AlQuran. Kata yang semakna dengannya juga ada dalam Taurat dan Injil. Kata syari'at dalam bahasa Ibrani disebutkan sebanyak $200 \mathrm{kali}$, yang selalu mengisyaratkan pada makna "kehendak Tuhan yang diwahyukan sebagai wujud kekuasaan-Nya atas segala perbuatan manusia." 6

Dalam Al-Quran kata syari'ah disebutkan hanya sekali dalam Surah Al-Jatsiyah, "Kemudian Kami Jadikan kamu berada didalam suatu syariat (peraturan) dari urusan (agama) itu, maka ikutilah syariat itu dan janganlah kamu mengikuti hawa nafsu orang-orang yang tidak mengetahui" (QS Al-Jatsiyah: 18).

Kemudian kata itu muncul dalam bentuk kata kerja ( $f i^{\prime} i l$ ) dan derivatnya (turunannya) sebagai berikut: "Dia telah mensyariatkan bagi kamu tentang agama apa yang telah diwasiatkan_Nya kepada Nuh dan apa yang telah Kami wahyukan kepadamu, dan apa yang telah kami wasiatkan kepada Ibrahim, Musa dan Isa..." (QS Al-Syuura: 13).

"Apakah mereka mempunyai sembahan-sembahan selain Allah yang mensyariatkan untuk mereka agama yang tidak diizinkan Allah? Sekiranya tak ada ketetapan yang menetukan (dari Alllah), tentulah mereka telah dibinasakan. Dan sesunggguhnya orang-orang yang zalim itu akan memperoleh azab yang amat pedih" (QS. Al-Syuura: 21).

Kata syariah berasal dari kata syara'a al-syai'a yang berarti 'menerangkan' atau 'menjelaskan sesuatu'. Atau berasal dari kata syir'ah dan syari'ah yang berarti 'suatu tempat yang dijadikan sarana untuk mengambil air secara langsung sehingga orang yang mengambilnya tidak memerlukan bantuan alat lain. ${ }^{7}$

\footnotetext{
${ }^{3}$ Philip Kotler, Marketing Management Millenium Edition, Tenth Edition (New Jersey: Prentice-Hall Inc, 2001), h. 4

${ }^{4}$ Ibid., h. 2.

${ }^{5}$ Hermawan Kartajaya et al., MarkPlus On Strategy (Jakarta: PT Gramedia Pustaka Utama, 2002).

${ }^{6}$ Muhammad Abdul Ghani, The Spirituality in Business, (Jakarta: Pena Pundi Aksara, 2005).

${ }^{7}$ Lihat Mu'jam Alfazh Al-Quran Al-Karim (Kairo: Majma’ Al-Lughah Al-‘Arabiyyah, Juz. 2), h.13.
} 
Syaikh Al-Qardhawi mengatakan: "Cakupan dari pengertian syariah menurut pandangan Islam sangatlah luas dan komprehensif (al-syumul). Didalamnya mengandung makna mengatur seluruh aspek kehidupan, mulai dari aspek ibadah (hubungan manusia dengan Tuhannya), aspek keluarga (seperti nikah, talak, nafkah, wasiat, warisan), aspek bisnis (perdagangan, industri, perbankan, asuransi, utang-piutang, pemasaran, hibah), aspek ekonomi (permodalan, zakat, bait al-mal, fa'i, ghanimah), aspek hukum dan peradilan, aspek undang-undang hingga hubungan antar negara."

Karena marketing berhubungan erat dengan bisnis atau perdagangan, maka marketing adalah bentuk muamalah yang dibenarkan dalam Islam, sepanjang dalam segala proses transaksinya terpelihara dari hal-hal terlarang oleh ketentuan syariah. Maka, syariah marketing adalah sebuah disiplin bisnis strategis yang mengarahkan proses penciptaan, penawaran dan perubahan value dari suatu inisiator kepada stakeholders-nya, yang dalam keseluruhan prosesnya sesuai dengan akad dan prinsip-prinsip muamalah (bisnis) dalam Islam.

Ini artinya bahwa dalam syariah marketing, seluruh proses, baik proses penciptaan, proses penawaran, maupun proses perubahan nilai (value), tidak boleh ada hal-hal yang bertentangan dengan akad dan prinsip-prinsip muamalah yang Islami. Sepanjang hal tersebut dapat dijamin, dan penyimoangan prinsip-prinsip muamalah islami tidak terjadi dalam suatu transaksi apapun dalam pemasaran dapat dibolehkan.

Ada 4 karakteristik syariah marketing menurut Kartajaya dan Sula ${ }^{9}$ yang dapat menjadi panduan bagi para marketers sebagai berikut:

1. Teistis (rabbaniyyah): jiwa seorang syariah marketer meyakini bahwa hukum-hukum syariat yang teistis atau bersifat ketuhanan ini adalah yang paling adil, paling sempurna, paling selaras dengan segala bentuk kebaikan, paling dapat mencegah segala bentuk kerusakan, paling mampu mewujudkan kebenaran, memusnahkan kebatilan dan menyebarluaskan kemaslahatan.

2. Etis (akhlaqiyyah): Keistimewaan lain dari syariah marketer selain karena teistis (rabbaniyyah) juga karena ia sangat mengedepankan masalah akhlak (moral, etika) dalam seluruh aspek kegiatannya, karena nilai-nilai moral dan etika adalah nilai yang bersifat universalo, yang diajarkan oleh semua agama.

3. Realistis (al-waqi'iyyah) : syariah marketer adalah konsep pemasaran yang fleksibel, sebagaimana keluasan dan keluwesan syariah islamiyah yang melandasinya. Syariah marketer adalah para pemasar professional dengan penampilan yang bersih, rapid an bersahaja, apapun model atau gaya berpakaian yang dikenakannya, bekerja dengan mengedepankan nilai-nilai religius, kesalehan, aspek moral dan kejujuran dalan segala aktivitas pemasarannya.

4. Humanistis (insaniyyah): keistimewaan syariah marketer yang lain adalah sifatnya yang humanistis universal, yaitu bahwa syariah diciptakan untuk manusia agar derajatnya terangkat, sifat kemanusiaannya terjaga dan terpelihara, serta sifat-sifat kehewanannya dapat terkekang dengan panduan syariah. Syariat islam diciptakan untuk manusia sesuai dengan kapasitasnya tanpa menghiraukan ras, warna kulit, kebangsaan dan status.Hal inilah yang membuat syariah memiliki sifat universal sehingga menjadi syariah humanistis universal.

\footnotetext{
${ }^{8}$ Dr. Yusuf Al-Qardhawi, Madkhal Li Dirasah Al-Syari'ah Al-Islamiyyah (Kairo: Maktabah, 1990).

${ }^{9}$ Hermawan Kartajaya dan Muhammad Syakir Sula, Syariah Marketing (Cet. III; Bandung : Mizan, 2006), h. 28.
} 


\section{Implementasi Syariah Marketing}

Menurut credo keimanan Islam, Nabi Muhammad adalah Rasul terakhir yang diturunkan untuk menyempurnakan ajaran-ajaran Tuhan Yang Maha Esa, yang menjadi suri tauladan umat-Nya sebagaimana disebutkan dalam QS. Al-Ahzab ayat 21: "Sesungguhnya telah ada pada (diri) Rasulullah itu suri teladan yang baik bagimu (yaitu) bagi orang yang mengharap (rahmat) Allah dan (kedatangan) hari kiamat dan Dia banyak menyebut Allah.”

Akan tetapi pada sisi lain, Nabi Muhammad SAW., juga manusia biasa; beliau makan, minum, berkeluarga dan bertetangga, berbisnis dan berpolitik, serta sekaligus memimpin umat. Nabi Muhammad sebagai seorang pedagang memberikan contoh yang baik dalam setiap transaksi bisnisnya. Beliau melakukan transaksi secara jujur, adil dan tidak pernah membuat pelanggannya mengeluh, apalagi kecewa.Beliau selalu menepati janji dan mengantarkan barang dagangannya dengan standar kualitas sesuai dengan permintaan pelanggan. Reputasinya sebagai pedagang yang benar dan jujur telah tertanam dengan baik sejak muda. Beliau selalu memperlihatkan rasa tanggung jawab terhadap setiap transaksi yang dilakukan.

Afzalurrahman ketika menguraikan masalah prinsip-prinsip perdagangan Islam mengatakan: "Adalah merupakan suatu fakta sejarah bahwa Muhammad tidak hanya melakukan perdagangan dengan adil dan jujur, akan tetapi ia bahkan telah meletakkan prinsip-prinsip mendasar untuk hubungan dagang yang adil dan jujur itu. Kejujuran, keadilan dan konsistensi yang ia pegang teguh dalam transaksi-transaksi perdagangan telah menjadi teladan abadi dalam segala jenis masalah perdagangan. Ia selalu memperlihatkan rasa tanggung jawab dan integritas yang besar dalam berurusan dengan orang lain. Hal ini didukung oleh banyak contoh yang diriwayatkan oleh orang-orang yang berbeda, yang semuanya sempat melakukan transaksi dengannya."

Nabi Muhammad bukan saja sebagai seorang pedagang, beliau adalah seorang nabi dengan segala kebesaran dan kemuliannya. Nabi Muhammad sangat menganjurkan umatnya berbisnis (berdagang), karena berbisnis dapat menimbulkan kemandirian dan kesejahteraan bagi keluarga tanpa tergantung atau menjadi beban orang lain. Beliau pernah betkata, "Berdaganglah kamu, sebab dari sepuluh bagian penghidupan, sembilan diantaranya dihasilkan dari berdagang." Al-Quran juga memberi motivasi untuk berbisnis pada ayat berikut: "Tidak ada dosa bagimu untuk mencari karunia (rezeki hasil perniagaan) dari Tuhanmu." (QS. Al-Baqarah : 198). Dalam ayat lain disebutkan : "Allah menghalalkan jual beli dan mengharamkan riba" (QS. Al-Baqarah : 275).

Dalam transaksi bisnisnya sebagai pedagang professional tidak ada tawar menawar dan pertengkaran antara Nabi Muhammad dan para pelanggannya, sebagaimana sering disaksikan pada waktu itu di pasar-pasar sepanjang jazirah Arab. Segala permasalahan antara Muhammad dengan pelanggannya selalu diselesaikan dengan adil dan jujur, tetapi bahkan tetap meletakkan prinsip-prinsip dasar untuk hubungan dagang yang adil dan jujur tersebut.

Disini terlihat bahwa beliau tidak hanya bekerja secara professional, tetapi sikap profesionalisme beliau praktikkan pula ketika telah dilantik menjadi Nabi. Beliau memimpin

${ }^{10}$ Afzalurrahman, Encyclopaedia of Seerah, Vol. III, Buku ke tiga, London : The Muslim Schools Trust, 1982, diterjemahkan oleh Dewi Nurjulianti dkk., dengan judul Muhammad Sebagai Seorang Pedagang (Cet. I; Jakarta: Penerbit Yayasan Swarna Bhumi, 1995), h. 19. 
sahabat-sahabatnya dengan prinsip-prinsip profesionalisme; memberinya tugas sesuai dengan kemampuan dan kapasitas yang dimiliki. Tidak bersifat KKN, semuanya berjalan dengan professional dan tentunya dengan tuntunan Allah.

Nabi Muhammad benar-benar mengikuti prinsip-prinsip perdagangan yang adil dalam transaksi-transaksinya. Beliau telah mengikis habis transaksi-transaksi dagang dari segala macam praktik yang mengandung unsur penipuan, riba, judi, gharar, keraguan, eksploitasi, pengambilan untung yang berlebihan dan pasar gelap. Beliau juga melakukan standardisasi timbangan dan ukuran, serta melarang orang-orang menggunakan timbangan dan ukuran lain yang tidak dapat dijadikan pegangan standar.

Nabi Muhammad juga mengatakan, "pedagang, pada hari kebangkitan akan dibangkitkan sebagai pelaku kejahatan, kecuali mereka yang bertakwa kepada Allah, jujur, dan selalu berkata benar" (HR Al Tirmidzi, Ibn Majah, dan Al Darimi).

Nabi Muhammad melarang beberapa jenis perdagangan, baik karena sistemnya maupun karena ada unsur-unsur yang diharamkan didalamnya. Memperjual-belikan benda-benda yang dilarang dalam Al-Quran adalah haram. Al Quran, misalnya, melarang mengkonsumsi daging babi, darah, bangkai dan alkohol, sebagaimana yang tercantum dalam QS Al-Baqarah:175.

"Barang yang bersih" berarti sehat dan diperoleh dengan cara yang halal. Karena itu apa yang dihasilkannya pun menjadi halal.

Ada sembilan etika pemasar, ${ }^{11}$ yang akan menjadi prinsip-prinsip bagi syariah marketer dalam menjalankan fungi-fungsi pemasaran, yaitu:

1. Memiliki kepribadian spiritual (takwa)

2. $\quad$ Berprilaku bail dan simpatik (Shidq)

3. Berprilaku adil dalam bisnis (Al-Adl)

4. Bersikap melayani dan rendah hati (Khidmah)

5. Menepati janji dan tidak curang

6. Jujur dan terpercaya (Al- Amanah)

7. Tidak suka berburuk sangka (Su'uzh-zhann)

8. Tidak suka menjelek-jelekkan (Ghibah)

9. Tidak melakukan sogok (Riswah)

\section{Membangun Bisnis dengan Nilai-nilai Syariah}

Ada empat hal yang menjadi key success factors (KSF) dalam mengelola suatu bisnis, agar mendapat celupan nilai-nilai moral yang tinggi. ${ }^{12}$ Untuk memudahkan mengingat, kita singkat dengan SAFT, yaitu:

a. Shiddiq (benar dan jujur) : jika seorang pemimpin senantiasa berprilaku benar dan jujur dalam sepanjang kepemimpinannya, jika seorang pemasarsifat shiddiq haruslah menjiwai seluruh prilakunya dalam melakukan pemasaran, dalam berhubungan dengan pelanggan, dalam bertransaksi dengan nasabah, dan dalam membuat perjanjian dengan mitra bisnisnya.

b. Amanah (terpercaya, kredibel): artinya, dapat dipercaya, bertanggung jawab, dan kredibel, juga bermakna keinginan untuk untuk memenuhi sesuatu sesuai dengan

\footnotetext{
${ }^{11}$ Hermawan Kartajaya dan Muhammad Syakir Sula, op. cit., h. 104.

${ }^{12}$ Ibid., h. 160.
} 
ketentuan. Diantara nilai yang terkait dengan kejujuran dan melengkapinya adalah amanah.

c. Fathanah (cerdas) : dapat diartikan sebagai intelektual, kecerdikan atau kebijaksanaan. Pemimpin yang fathanah adalah pemimpin yang memahami, mengerti dan menghayati secara mendalam segala hal yang menjadi tugas dan kewajibannya.

d. Thabligh (komunikatif) : artinya komunikatif dan argumentatif. Orang yang memiliki sifat ini akan menyampaikannya denga benar (berbobot dan dengan tutur kata yang tepat (bi al-hikmah). Berbicara dengan orang lain dengan sesuatu yang mudah dipahaminya, berdiskusi dan melakukan presentasi bisnis dengan bahsa yang mudah dipahami sehingga orang tersebut mudah memahami pesan bisnis yang ingin kita sampaikan.

Keempat KSF ini merupakan sifat-sifat Nabi Muhammad Saw yang sudah sangat dikenal di kalangan ulama tapi masih jarang diimplementasikan khususnya dalam dunia bisnis. ${ }^{13}$

\section{Marketing Syariah}

\section{Sekilas tentang Sustainable Marketing Enterprise (SME)}

Ketertarikan untuk membahas syariah marketing ini adalah karena adanya perubahan lanskap perekonomian dunia. Selama puluhan tahun, dunia hanya mengenal system ekonomi kapitalisme. Namun pada akhir 1970-an dan wal 1980-an, system ekonomi Islam atau yang dikenal juga sebagi system ekonomi syariah mulai bermunculan di Negara-negara Timur Tengah.

Dalam model SME, konsep pemasaran disini tidaklah berarti pemasaran sebagi sebuah fungsiatau departemen dalam perusahaan, tetapi bagaimana kita bisa melihat pasar secara kreatif dan inovatif. Pemasaran bukanlah hanya seperti anggapan orang, yaitu study untuk menjual. Atau seperti yang dipahami beberapa kalangan hanyalah marketing mix semata, yaitu pembuatan strategi untuk produk (product), harga (price), tempat (place) atau promosi (promotion). Namun pengertian terhadap pemasaran itu sendiri cakupannya lebih luas.

Pemasaran dapat didefinisikan sebagai sebuah disiplin bisnis strategis yang mengarahkan proses penciptaan, penawaran, dan perubahan values dari satu inisiator kepada stakeholdersnya. Seperti yang tertulis dalam buku Rethinking Marketing : Sustainable Marketing Enterprise in Asia, ${ }^{14}$ inspirasi menyangkut sebuah mimpi (dream), kultur menyangkut kepribadian (personality), dan institusi menyangkut aktivitas (activity). Oleh karenanya, agar sukses kita harus mempunyai impian yang akan menjadi driver dan konsisten dalam melakukan aktivitas.

Ada 17 prinsip syariah marketing sebagai berikut ${ }^{15}$ :

- Prinsip 1 : Information Technology Allows Us to be Transparent (change)

- Prinsip 2 : Be Respectful to your Competitors (Competitor)

${ }^{13}$ Baca lebih lanjut tentang sifat-sifat Nabi Muhammad dalam buku Muhammad Husein Haikal, Hayat Muhammad (Sejarah hidup Muhammad, terj.) Tintamas, 1984.

${ }^{14}$ Mengenai konsep Suistainable Marketing Enterprise (SME) ini dapat dibaca lebih lanjut pada buku Rethinking Marketing Suistainable Marketing Enterprise in Asia, karya Philip Kotler et.al, terbitan Prentice Hall, 2002.

${ }^{15}$ Hermawan Kartajaya dan Muhammad Syakir Sula, op. cit., h. 182. 
- Prinsip 3 : The Emergence of Customers Global Paradox (Cuctomer)

- Prinsip 4 : Develop A Spiritual-Based Organization (Company)

- Prinsip 5 : View Market Universally (Segmentation)

- Prinsip 6 : Target Costumer's Heart and Soul (Targeting)

- Prinsip 7 : Build A Belief System (Positioning)

- Prinsip 8 : Differ Yourself with A Good Package of Content and Context (Differentiation)

- Prinsip 9 : Be Honest with Your 4 Ps (Marketing-mix)

- Prinsip 10 : Practice A Relationship-based Selling (Selling)

- Prinsip 11 : Use A spiritual Barand Character (Brand)

- Prinsip 12 : Services Should Have the Ability to Transform (Service)

- Prinsip 13 : Practice A reliable Business Process (Process)

- Prinsip 14 : Create Value to Your Stakeholders (Scorecard)

- Prinsip 15 : Create A Noble Cause (Inspiration)

- Prinsip 16 : Develop An Ethical Corporate Culture (Culture)

- Prinsip 17 : Measurement Must Be Clear and Transparent (Institution)

Ketujuh belas prinsip tersebut dibuat berdasarkan pengamatan terhadap peran pemasaran untuk pasar syariah. Keempat prinsip pertama menjelaskan lanskap bisnis syariah (4CDiamond) yang terdiri dari change, competitor, customer dan company. Ketiga elemen utama adalah elemen utama dari lanskap bisnis, sedangkan factor terakhitr, company adalah berbagai factor internal yang penting dalam proses pembuatan strategi.

Sembilan prinsip berikutnya (prinsip 5 - prinsip13) menerangkan sembilan elemen dari Arsitektur Bisnis Strategis. Yang dibagi menjadi tiga paradigma, yaitu:

- Syariah Marketing Strategy untuk memenangkan mind-share,

- Syariah Marketing Tactic unutuk memenangkan market-share, dan

- Syariah Marketing Value untuk memenangkan heart -share.

Dalam syariah marketing strategy yang pertama harus dilakukan dalam mengeksplorasi pasar. Besarnya ukuran pasar (market size), pertumbuhan pasar (market growth), keungguklan kompetitif (competitive advantages) dan situasi persaingan (competitive situation).

Setelah menyusun strategi, kita harus menyusun taktik untuk memenangkan market-share yang disebut Syariah Marketing Tactic. Pertama-tama, setelah mempunyai positioning yang jelas di benak masyarakat, perusahaan harus membedakan diri dari perusahaan lain yang sejenis. Untuk itu diperlukan differensiasi sebagai core tactic dalam segi content (apa yang ditawarkan), context (bagaimana menawarkannya) dan infrastruktur (yang mencakup karyawan, faslitas dan teknologi). Kemudian menerapkan differensiasi secara kreatif pada marketing mix (product, price, place, promotion). Karena itu marketing-mix disebut sebagai creation tactic. Walaupun bergitu selling yang memegang peranan penting sebagai capture tactic juga harus diperhatikan karena merupakan elemen penting yang berhubungan dengan kegiatan transaksi dan langsung mampu menghasilkan pendapatan.

Dalam Syariah Marketing Value, bahwa strategi dan taktik yang sudah dirancang dengan penuh perhitungan tidaklah berjalan dengan baik bila tidak disertai dengan value dari produk atau jasa yang ditawarkan. Pelanggan biasanya mementingkan manfaat atau value apa yang didapat jika ia diharuskan berkorban sekian rupiah. Untuk itu, membangun value preposition bagi produk atau jasa kita sangatlah penting. 
Rumusan value preposition ini adalah sebagai berikut: ${ }^{16}$

Value preposition $=$

Total Get_Functional Benefit $(\mathrm{Fb})+$ Emotional Benefit $(\mathrm{Eb})$

Total Give Price $(\mathrm{P})+$ Other Expenses $(\mathrm{Oe})$

Pada dasarnya terdapat lima generic value strategy:

a. More for more, adalah formula value yang menawarkan total get $(\mathrm{Fb}+\mathrm{Eb})$ dan total give $(\mathrm{P}+\mathrm{Oe})$ yang lebih tinggi dibandingkan value yang ditawarkan pesaing;

b. More for same, menawarkan total get yang lebih tinggi dan total give yang sama;

c. More for less, menawarkan total get yang lebih tinggi dan total give yang lebih rendah;

d. Same for less, menawarkan total get yang samadan total give yang lebih rendah;

e. Less for less, menawarkan total get dan total give yang lebih rendah dibandingkan pesaing.

Prinsip selanjutnya, Prinsip 14, menjelaskan Syariah Scored yang bermakna bahwa anda harus terus menerus menyeimbangkan proposisi-proposisi nilai anda yang sesuai dengan prinsip-prinsip syariah tadi kepada tiga stakeholders utama yaitu karyawan (people), pelanggan (customer), dan pemegang saham (share-holders). Itulah maka penulis menyebutkan PCS-Circle.

Kemudian tiga prinsip terakhir (prinsip 15 sampai prinsip 17) adalah prinsip-prinsip yang membahas tentang inspirasi (inspiration), Buday (culture), dan institusi (institution. Ketiganya disebut sebagai Syariah Enterprise. Inspirasi menyangkut impian: sebuah perusahaan harus memiliki sebuah impian yang akan memberikan inspiras, membimbing dan merangsang semua orang yang ada didalamnya. Budaya menyangkut kepribadian; sebuah perusahaan harus memiliki kepribadian yang kuat, yang memberikan "perekat"yang menyatukan organisasi itu pada saat tumbuh dan berkembang. Akhirnya, institusi adalah tentang aktivitas: sebuah perusahaan harus mampu mengelola aktivitas-aktivitasnya dengan efisien dan efektif untuk merealisasikan visi serta sasaran-sasarannya.

Tentu saja, ketiga elemen Syariah Enterprise ini juga harus berlandaskan nilai-nilai syariah. Sebuah perusahaan tidaklah bisa memiliki inspirasi untuk menjadi economic animal semata tanpa peduli nilai-nilai lingkungan dan pemberdayaan komunitas disekitarnya. Budaya perusahaanpun harus dilandasi syariah; dengan menerapkan nilai-nilai luhur yang mesti dianut setiap karyawannya.

${ }^{16}$ Ibid., h. 186. 


\section{Daftar Pustaka}

Al Quran Al-Karim, lembaga Pencetakan Al Quran Raja Fahd, 1418 H.

Afzalurrahman, Encyclopaedia of Seerah, Vol. III, Buku ke tiga, London : The Muslim Schools Trust, 1982, diterjemahkan oleh Dewi Nurjulianti dkk., dengan judul Muhammad Sebagai Seorang Pedagang (Jakarta: Penerbit Yayasan Swarna Bhumi, Cet. I, 1995).

Covey, Stephen R., The $8^{\text {th }}$ Habits From Effectiveness to Greatness (Simon Schuster, New York, London, Toronto, Sydney, 2004).

Ghani, Muhammad Abdul, The Spirituality in Business (Jakarta: Pena Pundi Aksara, 2005).

Haikal, Muhammad Husein, Hayat Muhammad: Sejarah hidup Muhammad, terj. (Tintamas, 1984).

Kartajaya, Hermawan et al., MarkPlus On Strategy (Jakarta: PT. Gramedia Pustaka Utama, 2002).

Kartajaya, Hermawan, dan Sula, Muhammad Syakir, Syariah Marketing (Cet. III; Bandung: Mizan, 2006).

Kotler, Philip, Marketing Management Millenium Edition (Tenth Edition, Prentice-Hall Inc, New Jersey, 2001).

Kotler, Philip et.al, Rethinking Marketing Suistainable Marketing Enterprise in Asia (Prentice Hall, 2002).

Mu’jam Alfazh Al-Quran Al-Karim (Kairo: Majma’ Al-Lughah Al-'Arabiyyah, juz 2).

Qardhawi, Dr. Yusuf, Madkhal Li Dirasah Al-Syari'ah Al-Islamiyyah (Kairo: Maktabah, 1990).

Zohar, Danah dan Marshall, Ian, Spiritual Capital: Wealth We Can Live By Using Our Rational, Emotional, and Spiritual Intelligence to Transform Ourselves and Corporate Culture (Bloombury Publishing Plc : London, 2004). 